\title{
PEMBERDAYAAN MASYARAKAT DALAM PENGELOLAAN KESEHATAN MELALUI PENDEKATAN ADAPTIVE CONSERVATION DI KELURAHAN PADASUKA KOTA BANDUNG
}

\section{COMMUNITY EMPOWERMENT IN HEALTH MANAGEMENT THROUGH ADAPTIVE CONSERVATION APPROACH IN PADASUKA BANDUNG}

\author{
${ }^{1)}$ Suci Tuty Putri, ${ }^{2)}$ Septian Andriyani, ${ }^{3)}$ Sehabudin Salasa, ${ }^{4)}$ Tirta Adikusuma \\ ${ }^{1,2,3,4}$ Program Studi D3 Keperawatan FPOK Universitas Pendidikan Indonesia \\ J1. Dr. Setiabudi No.229 Bandung \\ Email : ${ }^{1}$ suci.putri@upi.edu
}

\begin{abstract}
ABSTRAK
Meningkatnya jumlah lansia maka secara tidak langsung menjadi faktor meningkatnya berbagai penyakit degeneratif. Namun ternyata cakupan pelayanan kesehatan bagi lansia dikota Bandung masih rendah Penyakit yang timbul pada lansia tersebut seharusnya dapat dicegah dengan peningkatan kesadaran masyarakat untuk mengontrol faktor - faktor risikonya melalui program peningkatan pelayanan kesehatan dan pemberdayaan lansia. Pemberdayaan lansia dengan model Adaptif Conservation yaitu kemampuan beradaptasi masyarakat dalam penyelesaian masalah kesehatan dilakukan secara bersama-sama melibatkan semua unsur energi, struktur, integritas pribadi dan sosial. Tujuan program adalah untuk menyusun dan melaksanakan program pengembangan pemberdayaan lansia. Metode yang digunakan adalah survey, MMD, screening kesehatan, pelatihan kader dan penyuluhan kesehatan. Program di laksanakan selama 8 bulan. Subjek adalah semua unsur masyarakat, kader kesehatan yang ada di Kelurahan Padasuka. Hasil dari kegiatan adalah diperolehnya data mengenai kesehatan masyarakat, kondisi penyakit lansia, peningkatan pengetahuan kader mengenai manajemen Posbindu.
\end{abstract}

Keyword : Adaptif conservation; Pemberdayaan lansia; Pelatihan kader

\section{ABSTRACT}

Increasing the number of eldery indirectly become factors of increasing various degenerative diseases. However, the coverage of health service for elderly is still low. Diseases that arise in the elderly should be prevented by increasing public awareness to control the risk factors through improvement programs of health service and empowerment of the elderly. Empowering of elderly with Adaptif Conservation model is the ability to adapt society in solving health problems done together to involve all elements of energy, structure, personal and social integrity. The purpose of the program is to develop and implement the empowerment development program of the elderly. Program is implemented for 8 months. Subjects are all elements of society, health in Padasuka Village. The method uses is starts with surveys, village community meetings, health screening programs, health promotion, comunnity health volunteer training, and health education. The result of the activity is the real data about the condition of health comunnity, elderly diseases, the increase of physical and social activity of the elderly and the existence of knowledge refreshment about Posbindu management.

Keyword : Adaptif conservation; Empowering of elderly; Comunnity health volunteer training

Submitted : 21 Nopember 2017

Revision : 3 April 2018

Accepted : 5 Juni 2018

\section{PENDAHULUAN}

Program di bidang kesehatan digulirkan pemerintah guna mencapai target dan tujuan Nasional yang tertuang dalam MDGs (Millennium Development Goals). Sasaran dalam program-program MDGs antara lain adalah pendidikan, kemiskinan, kelaparan, kesehatan, lingkungan hidup, kesetaraan gender, dan 
pemberdayaan perempuan. MDGs adalah komitmen negara terhadap rakyat Indonesia dan komitmen Indonesia kepada masyarakat global guna memperbaiki kesejahteraan masyarakat (Dinkes, 2012).

Dinas Kesehatan Kota Bandung mencanangkan visi dalam bidang kesehatan yaitu masyarakat Bandung yang mandiri untuk hidup sehat. Untuk mewujudkan pencapaian tersebut dilakukan berbagai strategi antara lain (1). Meningkatkan kualitas dan akses pelayanan kesehatan dasar dan rujukan yang bermutu, merata dan terjangkau. (2) meningkatkan kualitas lingkungan bersih melalui sanitasi dasar dan sanitasi umum.

(3) Meningkatkan promosi dan pemberdayaan masyarakat dalam pembangunan kesehatan. (4) Meningkatkan kebijakan dan manajemen pembangunan kesehatan(Dinkes, 2012).

Misi yang begitu besar tersebut tidak akan berjalan jikahanya dilakukan oleh tenaga kesehatan semata. Peran Serta Masyarakat (PSM) diperlukan sebagai sumber daya pelaksanaan kegiatan. Sebagaimana dikemukakan Depkes RI (1992), PSM adalah proses dimana individu, keluarga, lembaga swadaya masyarakat, dunia usaha dan masyarakat luas pada umumnya: (1) Mengambil tanggung jawab atas kesehatan dan kesejahteraan diri sendiri, keluarga dan masyarakat; (2) Mengembangkan kemampuan berkontribusi dalam upaya peningkatan kesehatan mereka sendiri dan masyarakat serta termotivasi untuk memecahkan masalah kesehatan yang dihadapinya; (3) Menjadi agen atau perintis pembangunan kesehatan dan kepemimpinan dalam pergerakan kegiatan masyarakat di bidang kesehatan, yang dilandasi semangat gotong royong.

Strategi pelayanan kesehatan dijalankan melalui kemitraan dalam kerja sama (partnership), pendidikan kesehatan, dan proses kelompok yang melibatkan peran serta aktif seluruh masyarakat dalam kegiatannya. Pemecahan masalah yang dilakukan meliputi kegiatan pembinaan keluarga secara langsung, penyuluhan kelompok dan masyarakat umum termasuk juga penyegaran kader. Berbagai program promotif dan preventif dilakukan untuk mencegah meningkatnya angka mortalitas dan morbiditas pada kelompok masyarakat. Salah satu upaya program promotif dan preventif adalah pemberdayaan lansia, dimana lansia menjadi kelompok yang memiliki risiko besar terhadap timbulnya masalah kesehatan.

Pemberdayaan lansia dapat dilakukan dengan berbagai pendekatan salah satunya adalah model Adaptif Conservation yang kembangkan oleh Mary Levine (1967-1989). Model ini menunjukkan dimana penyelesaian masalah kesehatan dilakukan secara bersama-sama melibatkan semua unsur energi, struktur, integritas pribadi dan sosial. Dengan kemampuan individu untuk dapat beradaptasi maka kesehatan dapat dicapai dengan optimal jika proses adaptasi ini dilakukan dengan konsevasi (Anonim, 2013).

Kelompok lansia menjadi salah satu kelompok usia yang jumlahnya terus menerus meningkat, kelompok ini juga rentan terhadap berbagai penyakit. Data di Indonesia menggambarkan suatu kondisi terjadinya peningkatan jumlah penduduk lansia yang semakin meningkat dan kenaikan data tersebut disinyalir akan semakin meningkat pada 10 tahun kedepan. Menurunnya cakupan pelayanan kesehatan dapat berakibat buruk bagi kualitas hidup lansia. Hasil penelitian yang di lakukan peneliti mengenai kualitas hidup lansia yang tinggal di komunitas dan yang tinggal di rumah di kota Bandung, didapatkan hasil bahwa pemenuhan domain fisik atau fisiologis lansia yang tinggal di rumah masih rendah dengan cakupan $31 \%$ kualitasnya rendah, dan domain psikologi $30 \%$ kualitasnya rendah(Putri, Fitriana,\& Ningrum, 2015). Berbagai penyakit yang umum mengenai 
lansia adalah penyakit muskuloskeletal, kardiovaskuler, urogenital, pernafasan, dan Endokrin.

Kelurahan Padasuka Kota Bandung merupakan salah satu mitra pendidikan Program Studi D3 Keperawatan FPOK UPI. Salah satu bahan kajian yang sedang dikembangkan adalah model pengembangan pemberdayaan lansia. Hal ini di ambil karena Program Studi D3 Keperawatan memiliki kekhususan dalam bidang gerontologi (kajian lansia). Berdasarkan hasil survey yang di lakukan di Kelurahan Padasuka, jumlah lansia meningkat dari tahun ketahun, tercatat jumlah lansia di Kelurahan Padasuka tahun 2013 adalah 1551 orang atau sekitar $11,5 \%$ dari jumlah penduduk.

Meningkatnya jumlah lansia maka secara tidak langsung menjadi faktor meningkatnya berbagai penyakit degeneratif salah satunya adalah Diabetes Melitus. Diabetes melitus merupakan suatu kumpulan gejala yang timbul pada seseorang yang disebabkan oleh karena adanya peningkatan kadar glukosa darah akibat penurunan sekresi insulin yang progresif dilatar belakangi oleh resistensi insulin (Soegondo, 2009). Komplikasi yang sering ditimbulkan yaitu stroke, gagal ginjal, jantung, nefropati, dan gangren. Menurut data dari organisasi kesehatan di dunia World Health Organisation (WHO) diperkirakan jumlah diabetes mellitus di Indonesia mencapai 21,3 juta orang pada tahun 2030 sedangkan dari International Diabetes Federation (IDF) diperkirakan jumlah penderita diabetes melitus mencapai lebih dari 371 juta jiwa di seluruh dunia yang berusia antara 20-79 tahun. Penyakit tersebut seharusnya dapat dicegah dengan peningkatan kesadaran masyarakat untuk mengontrol faktor - faktor risikonya. Peran serta UPI sebagai salah satu institusi yang menyelenggarakan pendidikan kesehatan adalah bekerjasama dengan lintas sektoral untuk meningkatkan kesadaran masyarakat mengenai kesehatan yang pada akhirnya meningkatkan kualitas hidup manusia. Oleh karena itu, tujuan kegiatan ini adalah untuk menyusun dan melaksanakan program pengembangan pemberdayaan masyarakat, khususnya lansia dengan metode adaptive conservation.

\section{METODE PELAKSANAAN}

Pendekatan adaptive conservation dilakukan secara bertahap guna tercapainya peran serta masyarakat yang berperan aktif dalam pencegahan maupun pendampingan pada penderita diabetes melitus khususnya dan penyakit degeneratif lainnya. Metode pelaksanaan yang digunakan dengan pendekatan adaptive conservation diantaranya pendataan status kesehatan masyarakat dengan survey mawas diri, penyuluhan kesehatan, screening kesehatan terhadap lansia dan pelatihan terhadap kader posbindu. Secara umum pelaksanaan PKM digambarkan pada bagan berikut. 


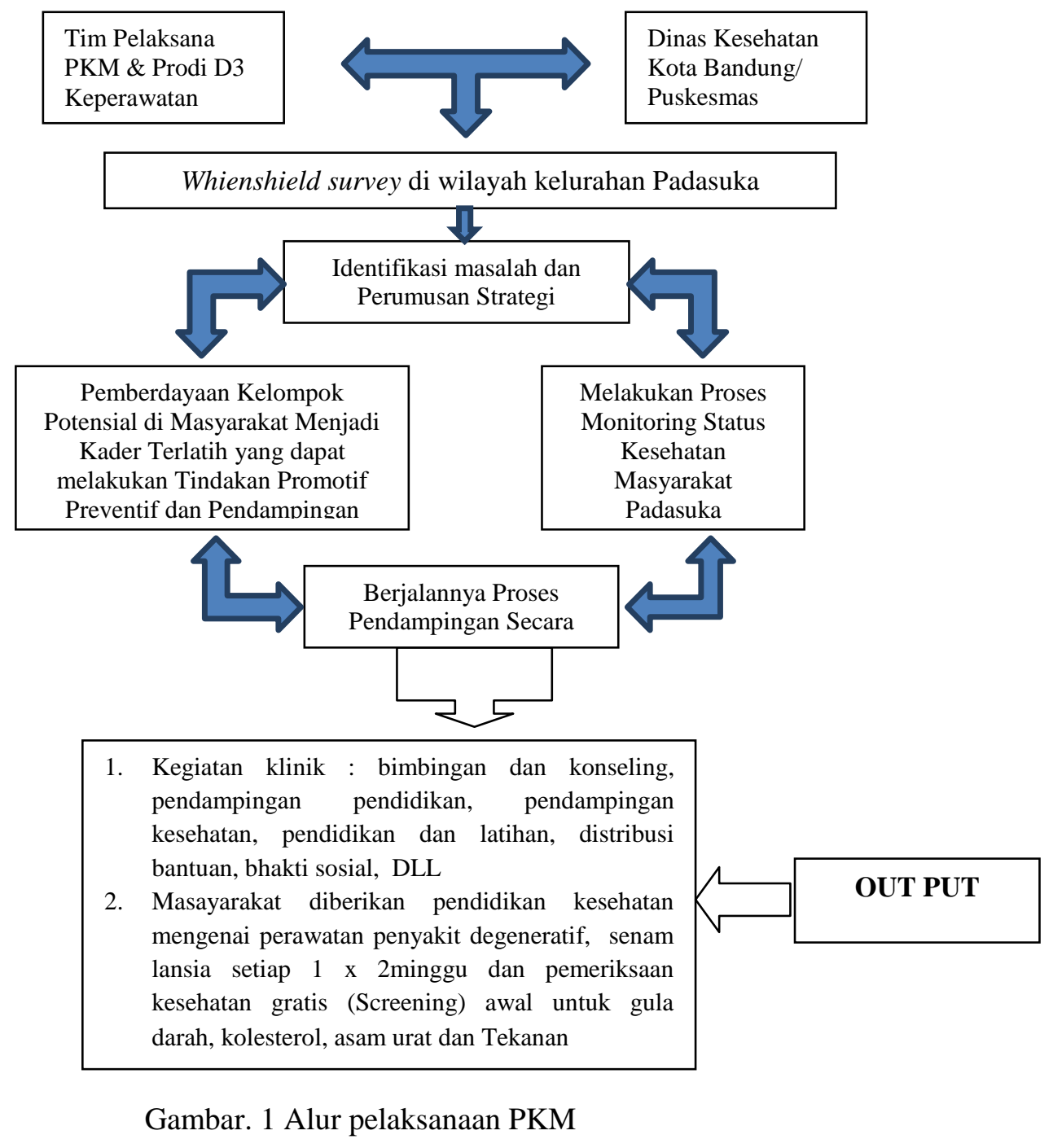

Proses yang dilakukan pada tahap pertama dalam program ini diikuti oleh 59 orang yang terdiri dari masyarakat dari RW 04 dan RW 05 Kelurahan Padasuka,

\section{HASIL DAN PEMBAHASAN}

\section{Program Survey dan Screening Kesehatan}

Pelaksanaan program pemberdayaan masyarakat melalui pendekatan adaptive conservationdalam pengelolaan didapatkan hasil, meningkatnya partisipasi masyarakat dalam pelaksanaan program menumbuhkan kultur perilaku hidup sehat.

Dalam pelaksanaan survey mawas diri dan screning diperoleh data hasil status petugas puskesmas Padasuka, serta Dosen dan Staf Prodi D3 Keperawatan FPOK UPI.

kesehatan lansia yaitu status kesehatan lansia, nilai Gula darah, Kolesterol, Asam Urat dan tekanan darah.

\section{Program Senam Lansia dan Pelatihan Instruktur Senam}

Program ini bertujuan untuk memberdayakan kader kesehatan atau masyarakat yang memiliki kemampuan dan keinginan untuk menjadi instruktur senam lansia. Sehingga, masyarakat memiliki SDM yang mampu menjadi instruktur senam pada setiap kegiatan senam rutin. 
Program ini berlangsung selama 3 bulan dan di lakukan setiap 2 minggu sekali. Masyarakat dan kader sangat antusias mengikuti kegiatan senam dan pelatihan instruktur senam. Pada akhir kegiatan kader yang menyatakan diri siap untuk menjadi instruktur masih sangat sedikit yaitu 1 orang.

\section{Program Pelatihan Kader Kesehatan}

Seminar dan workshop Manajemen Posbindu dilaksanakan dengan baik sesuai dengan rencana kegiatan. Seminar berisi materi mengenai manajemen Posbindu, Penyakit pada lansia dan Pengkajian Kesehatan pada lansia yang di ikuti oleh 40 kader Posbindu di wilayah Puskesmas Padasuka.

Program pemberdayaan masyarakat melalui pendekatan adaptive conservation dalam pengelolaan lansia merupakan suatu program yang dirancang secara terstruktur dan sistematis, dimana dengan pendekatan tersebut intervensi yang dilakukan akan sesuai dengan kebutuhan yang ada di masyarakat dan lingkungan. Pendekatan adaptive conservation menuntut masyarakat agar berperanserta secara aktif, dimana keberadaan fasilitator dari Dinas Kesehatan maupun lembaga pendidikan Prodi D3 Keperawatan UPI sebatas membaNtu terselenggaranya program serta mengarahkan masyarakat agar dapat menyelesaikan permasalahan kesehatan khususnya pengelolaan DM di lingkungannya.

Pendekatan adaptive conservation sejalan dengan pemberdayaan masyarakat dengan harapan mampu mengubah kesadaran masyarakat akan ancaman kesehatan dari penyakit tidak menular. Kelompok lansia menjadi salah satu kelompok usia yang jumlahnya terus menerus meningkat, kelompok ini juga rentan terhadap berbagai penyakit. Data di Indonesia menggambarkan suatu kondisi terjadinya peningkatan jumlah penduduk lansia yang semakin meningkat dan kenaikan data tersebut disinyalir akan semakin meningkat pada 10 tahun kedepan. Hasil penelitian yang di lakukan peneliti mengenai kualitas hidup lansia yang tinggal di komunitas dan yang tinggal di rumah di kota Bandung, didapatkan hasil bahwa pemenuhan domain fisik/ fisiologis lansia yang tinggal di rumah masih rendah dengan cakupan $31 \%$ kualitasnya rendah, dan domain psikologi $30 \%$ kualitasnya rendah(Putri, Fitriana, \& Ningrum, 2015). Layanan perawatan kesehatan untuk lansia harus termasuk, promosi kesehatan, perawatan sehari-hari, pendidikan pencegahan, olahraga, dan nutrisi. Kesehatan pendidikan harus memperhatikan kebutuhan dan tingkat kognitif mereka(Putri \& Andriyani, 2008).

Berbagai penyakit yang umum mengenai lansia adalah penyakit muskuloskeletal, kardiovaskuler, urogenital dan pernafasan, endokrin. Adapun penyakit degeneratif salah satunya adalah Diabetes Melitus. Orang yang memasuki usia 55 tahun keatas, berkaitan dengan terjadinya diabetes karena pada usia tua, fungsi tubuh secara fisiologis menurun karena terjadi penurunan sekresi atau resistensi insulin sehingga kemampuan fungsi tubuh terhadap pengendalian glukosa darah yang tinggi kurang optimal (Suyono, 2011). Diabetes melitus merupakan penyakit kronis yang tidak dapat disembuhkan namun dapat di kontrol. Penderita diabetes melitus membutuhkan perawatan yang berkesinambungan untuk meningkatkan kualitas hidup yang lebih baik. Salah satu cara yang dapat dilakukan untuk meningkatkan kualitas hidup yang lebih baik yaitu dengan cara melaksanakan strategi pemberdayaan. Menurut Woodall, Raine, South \& Booth (2010) strategi pemberdayaan yang dibutuhkan untuk meningkatkan kualitas hidup atau meningkatkan kesehatan pada penderita diabetes melitus dipengaruhi oleh lima 
bidang utama yakni peningkatan selfefficacy dan self-esteem, pengambilan kontrol yang lebih besar (greater sense of control), peningkatan pengetahuan dan kesadaran, perubahan perilaku, memperluas jaringan serta dukungan social (a greater sense of community, broadened social network and social support). Kelima strategi tersebut akan berpengaruh pada kualitas hidup apabila individu mempunyai kemauan untuk berubah. Individu dengan penyakit DM mempunyai tanggung jawab yang besar untuk mengatur dirinya sendiri dalam melakukan perubahan terutama perawatan pada penyakitnya. Kemampuan individu untuk mengontrol diri dan menentukan pilihan mengenai kesehatan mereka disebut dengan empowerment. Empowerment penderita DM dipengaruhi oleh beberapa faktor diantaranya jenis kelamin, usia, pendidikan, penghasilan dan lama menderita. Empowerment tersebut direalisasikan untuk membangun kepercayaan, meningkatkan harga diri, dan mengembangkan mekanisme koping untuk meningkatkan ketrampilan pribadi (Woodal, Raine, Shout, \& Booth, 2010). Seorang perawat dapat melaksanakan empowerment kepada penderita DM dengan menggunakan potensi lingkungannya yaitu dengan cara memandirikan diabetisi untuk merubah diabetisi dari tidak tahu menjadi tahu, dari tidak mampu menjadi mampu sesuai dengan keadaan diabetes dan keluarga serta kemauan diabetes untuk berubah. Dalam hal ini sangat diperlukan salah satunya adalah peran perawat dalam menjaga kualitas hidup pasien DM sangat penting, khususnya dalam meningkatkan kemampuan pasien dan keluarga agar dapat melakukan perawatan diri secara mandiri.

\section{Strategi}

empowerment dikembangkan pada pasien diabetes untuk meningkatkan kontrol mereka terhadap penyakitnya dengan cara meningkatkan aktivitas fisik, memperbaiki pola makan sehat dan meningkatkan kesehatan mental yang lebih baik dan sejahtera. Seorang perawat harus mampu mengintegrasikan semua aspek yang mendukung yaitu aspek individu dan lingkungan yang mampu memberdayakan diabetisi untuk menerapkan lima pilar dalam pengelolaan DM (McNamara et al, 2010). Pengelolaan penyakit DM menurut PERKENI, 2011 terdiri dari 5 pilar antara lain pengaturan diet, latihan fisik, obat, monitoring glukosa dan edukasi. Penyakit DM merupakan penyakit yang membutuhkan perawatan jangka panjang dan keterlibatan keluarga sehingga membutuhkan strategi perawatan, salah satunya melalui pemberdayaan pasien. Pemberdayaan bertujuan membentuk individu masyarakat menjadi mandiri yang meliputi kemandirian bertindak dan mengendalikan apa yang mereka lakukan demi penyelesaian pemecahan masalah yang dihadapi dengan menggunakan daya atau kemampuan yang dimiliki (Sulistiyani, 2014).

Sutandi (2012) mengemukakan bahwa perawat sebagai salah satu tenaga kesehatan, memiliki peranan yang strategis dalam memberikan kemampuan kepada keluarga dan pasien dalam melakukan penanganan secara mandiri. Sejumlah penelitian eksperimental memperlihatkan bahwa perawat mempunyai peran yang cukup berpengaruh terhadap perilaku pasien. Dengan memberikan pemahaman yang benar dan memberdayakan keluarga dan pasien dalam berpartisipasi untuk dapat melakukan perawatan diri secara mandiri (self-care), berbagai komplikasi yang mungkin akan muncul dapat dikendalikan dan pasien memiliki derajat kesehatan yang optimal. Beberapa penelitian mencatat bahwa 50-80\% diabetisi memiliki pengetahuan dan ketrampilan yang kurang dalam mengelola penyakitnya (Palestin, Ermawan, \& Donsu, 2005).

Kegiatan yang dilakukan khususnya untuk melihat dan menakar peranserta masyarakat dilakukan dengan bersifat rekreatif dalam hal ini kegiatan 
gerak jalan. Kemudian dalam melakukan exploring masalah-masalah kesehatan khususnya diabetes melitus dilakukan dengan cara wawancara serta pemeriksaan status kesehatan. Metode yang dilakukan dengan pendekatan tersebut dapat membantu masyarakat dalam merefleksikan keadaan yang ada serta tindakan apa yang dapat dilakukan sesuai kemampuan masyarakat sehingga dapat merubah persepsi yang sebelumnya sudah tertanam pada pikiran warga masyarakat tersebut. Hal ini akan lebih efektif dalam memupuk budaya baru pengelolaan kesehatan di masyarakat, karena kesadaran untuk saling menjaga dan melakukan sesuatu berasal dari masyarakat sendiri. Berbeda halnya jika upaya tersebut datang dari satu arah saja misalkan dari pemerintah dalam hal ini Dinas Kesehatan Kota Bandung atau dari Pihak pendidikan, maka masyarakat akan merasa tidak terlalu membutuhkan informasi atau kemampuan dalam pengelolaan kesehatan. Hal ini sejalan dengan Grizzell (2007) dalam teori planned behaviour dikatakan bahwa persepsi dapat mempengaruhi kontrol terhadap perilaku yang nantinya akan mengubah norma secara subjektif terhadap suatu masalah, sehingga akan menstimulasi niat atau upaya untuk melakukan sesuatu sehingga menjadi kebiasaan atau budaya baru.

Elemen yang tidak kalah penting dalam program ini yaitu masyarakat dapat merumuskan kegiatan apa yang dapat dilakukan untuk menunjang pengelolaan penyakit, dalam hal ini adalah Posbindu. Posbindu adalah bentuk partisipasi masyarakat untuk melakukan deteksi dini dan pemantauan faktor-faktor risiko penyakit tidak menular (NCD), dan di mana itu dilakukan secara terpadu, rutin dan berkala (Putri\& Andriyani, 2018) . Setelah dilakukan exploring masyarakat dapat mengidentifikasi kegiatan yang dapat dilakukan diantaranya penguatan pengetahuan dan keterampilan pengelolaan kesehatan di anataranya senam lansia dan manajemen posbindu. Hal ini sejalan dengan proses pemberdayaan yang di gaungkan Kemenkes tahun 2015, dimana prinsip pemberdayaan adalah adanya peran serta secara aktif dari masyarakat. Strategi yang dapat dilakukan dalam proses pemberdayaan masyarakat dalam pengelolaan penyakit tidak menular diantaranya pelatihan atau pendidikan dan pembinaan.

Pembinaan terhadap kader posbindu melalui seminar dan workshop merupakan upaya yang dilakukan unutk meningkatkan pengetahuan kader Posbindu dalam manajemen pelaksanaan program Posbindu, selain itu untuk meningkatkan kemampuan dan skill para kader dalam menghadapi para lansia.

Upaya pemberdayaan yang dilakukan untuk menstimulasi pola pikir masyarakat dalam pengelolaan penyakit pada lansia khususnya diabetes melitus yang berkelanjutan yang dilakukan dengan cara penyuluhan. Hal tersebut merubah, mendorong dan meningkatkan persepsi masyarakat terhadap faktor resiko yang mungkin timbul akibat penyakit tersebut. Upaya selanjutnya setelah masyarakat dilakukan penguatan mengenai aspek pengetahuan dan keterampilannyaa yaitu dengan cara diberikan kesempatan melakukan pengelolaan penyakit diabetes melitus di wilayahnya baik dengan bentuk kegiatan promotif/preventif maupun rehabilitatif (Maryam, 2008). Hal tersebut dapat memberi dampak dalam menumbuhkannya keyakinan masyarakat dalam melakukan tindakan pengelolaan diabetes tersebut atau dengan istilah lain masyarakat memiliki self efficacy yang positif.

Program yang digulirkan ini dengan pendekatan adaptive conservation menunjang untuk menumbuhkan self efficacy tersebut, hal tersebut dapat dilihat dari tahap-tahap pelaksanaan program dari mulai exploring sampai dengan rencana tindak lanjut. Dengan cara tersebut selain 
Suci Tuty Putri, Septian Andriyani, Sehabudin Salasa, Tirta Adikusuma

Pemberdayaan Masyarakat Dalam Pengelolaan Kesehatan Melalui Pendekatan Adaptive Conservation

di Kelurahan Padasuka Kota Bandung

upaya promotif dan preventif dapat dilakukan untuk mencegah meningkatnya angka penderita baru sedangkan proses rehabilitatif dapat dilakukan untuk mempercepat proses pemulihan dan memandirikan para penderita pasca perawatan.

\section{SIMPULAN}

Pemberdayaan masyarakat melalui pendekatan adaptive conservation di kelurahan padasuka kota bandung jawa barat menunjang dalam menyiapkan kelompok potensial di masyarakat yang dapat diberdayakan dan melakukan proses pendampingan dalam menekan masalah kesehatan terutama pada lansia. Hal tersebut terlihat dari tahapan pendekatan model tersebut yang berlangsung secara sistematis mulai dari pengkajian, perumusan masalah dan strategi penanggulangan, implementasi dan rencana tindaklanjut yang menunjang proses pembinaan guna menyongsong masyarakat sehat.

\section{DAFTAR PUSTAKA}

Anonim. (2013). Levine's Four Conservation Principles. Di akses melalui

http://currentnursing.com/nursing t heory/Levin_four_conservation_pri nciples.html

American Diabetes Association. (2010). Diagnosis and Classification of Diabetes Melitus. Diabetes Care, 33 (1), 62-69

Dinkes (2012). Profil Kesehatan Kota Bandung. Di akses melalui http://www.depkes.go.id/resources/ download/profil/PROFIL KAB K OTA_2011/P.Bandung_Kotabandu ng_11.pdf

Grizzell, J., 2007. Behavior change theories and models.Retrieved in January, 28, p.2007.
Kementerian Kesehatan Republik Indonesia. (2013). Diabetes Melitus Penyebab Kematian Nomor 6 Di Dunia: Kemenkes Tawarkan Solusi Cerdik Melalui Posbindu. Diakses Pada 10 Maret 2016.

Maryam, S. (2008). Menengenal Usia Lanjut dan Perawatannya. Penerbit Salemba.

McNamara, R., Robling, M., Hood, K., Bennert, K., Channon, S., Cohen, D., Crowne, E., Hambly, H., Hawthorne, K., Longo, M., Lowes, L., Playle, R., Rollnick, S., Gregory, J.W. (2010). Development and evaluation of a psychosocial intervention for children and teenagers experiencing diabetes (DEPICTED). BMC Health Services Research,12(36)

Palestin, B., Ermawan, B., \& Donsu, JDT. (2005). Penerapan Komunikasi Terapeutik Untuk Mengoreksi Perilaku Klien Rawat Jalan Dengan Diabetes Mellitus, Jurnal Teknologi Kesehatan 1(1): 1-10.

Putri, S. T., Fitriana, L. A., \& Ningrum, A. (2015). Studi Komparatif: Kualitas Hidup Lansia Yang Tinggal Bersama Keluarga Dan Panti. Jurnal Pendidikan Keperawatan Indonesia, 1(1), 1-6.

Putri, S. T., \& Andriyani, S. (2018). Needs and Problems of Posbindu Program: Community Health Volunteers Perspective. In IOP Conference Series: Materials Science and Engineering, 288, (1), p. 012139). IOP Publishing.

Soegondo, S. (2009). Penatalaksanaan Diabetes Melitus Terpadu. Jakarta: FKUI.

Sulistiyani. (2014). Kemitraan dan ModelModel Pemberdayaan. Yogyakarta: Gala Media 
Sutandi, A., \& Binawan, S. T. I. K. E. S. (2012). Self Management Education (DSME) Sebagai Metode Alternatif Dalam Perawatan Mandiri Pasien Diabetes Melitus Di Dalam Keluarga. Jurnal Manajemen, 29

Suyono, S. (2011). Penatalaksnaan DM Terpadu Patofisiologi DM (Ed.2). Jakarta: FKUI

Woodall, J., Raine, G., South, J., \& Warwick-Booth, L. (2010). Empowerment \& health and wellbeing: evidence review. 